\title{
Effect of morphology of primary a on fatigue crack propagation resistance in a near a heat resistant Titanium alloy.
}

\author{
Y. Sumi*, H. Takabayashi*, Hangyue Y. Li**, P. Bowen** \\ *R\&D Center, Daido Steel Co., LTD., Nagoya, Japan, y-sumi@ac.daido.co.jp \\ ** School of Metallurgy and Materials, University of Birmingham, Birmingham, UK
}

Keywords : Near a titanium alloy, Fatigue crack propagation

\begin{abstract}
DAT54 is a new near a heat resistant Ti alloy developed for disk applications in the compressor part of jet engines. DTA54 with bimodal microstructure shows a good balance of fatigue strength and creep life, and performs better than Ti-6242s up to $873 \mathrm{~K}$. However, the influence of microstructure on properties, especially the effect of the morphology of primary a on fatigue crack growth resistance is not understood. In this study, samples with different types of microstructure were prepared by applying different heat treatment temperatures, and the influence of microstructure on fatigue crack growth properties at ambient temperature and $823 \mathrm{~K}$ was investigated. Influence of environment was also investigated by testing in vacuum and in air condition. Acicular microstructure shows lower fatigue crack growth rates in Paris' region than the bimodal microstructures at $823 \mathrm{~K}$. For the bimodal structures, aspect ratio of primary a do not have apparent influence on fatigue crack growth rates in Paris' region, whereas fatigue threshold (DKth) seems to be affected by the morphology of primary a.
\end{abstract}

\section{$\underline{\text { 1. Introduction }}$}

As the world economic growth increase, the number of people traveling by airplane has been increasing, and huge number of consumer products is shipped worldwide by express delivery services. Therefore weight reduction of aircraft is important not only for improving the fuel efficiency but also increase of the capacity of passenger and luggage. Titanium alloys have been applied to aircraft parts because of their good strength to density ratio. Its excellent specific strength is the most beneficial when titanium alloys are used in rotating part of jet engine as substitution to conventional Ni base superalloys for improving the fuel efficiency [1]. Near a alloy shows excellent creep resistance up to about $873 \mathrm{~K}$ and used mainly as blades and disks in the compressor [2]. Near a type alloy DAT54 (Ti-5.8Al-4.0Sn-3.5Zr-2.8Mo-0.7Nb-0.35Si-0.06C) is a newly developed alloy, which shows better mechanical properties than conventional Ti-6242s (Ti-6Al-2Sn-4Zr-2Mo-0.1Si) and IMI834 [3, 4]. DAT54 exhibits balanced low cycle fatigue strength and creep strain rate contributed by the optimum volume fraction of primary a, which is $17 \%$ in the transformed beta microstructure [5]. However, an influence of the microstructure on properties, especially the effect of the morphology of primary a on fatigue crack growth is not well understood in this alloy. In this study, samples with different types of microstructure constructed by different heat treatment temperature were prepared, and the influence of microstructure on fatigue crack growth properties at ambient temperature and $823 \mathrm{~K}$ was investigated.

\section{Experimental Procedures.}

Table 1 shows the chemical composition of DAT54 material used for experiments. The material was cut from actual forged product and forged at the temperature of $\mathrm{a}+\mathrm{b}$ phase region into round bars. To obtain different morphology of the primary a, two different forging ratio in final forging was selected. Forged bars were then subjected to solution treatment at $1323 \mathrm{~K}$ and $1273 \mathrm{~K}$, above and below the b transus temperature ( $\mathrm{Tb}$ ) respectively. Samples were aged at $908 \mathrm{~K}$ for 3.6ks after the solution treatment, followed by air cooling. The microstructures were observed by an optical microscope. Fatigue crack growth tests were conducted in air and vacuum, at room temperature and at $823 \mathrm{~K}$ under constant amplitude load with a load ratio of 0.1 and frequency of $0.25 \mathrm{~Hz}$. To find out the threshold of stress intensity factor (DK threshold), a load shedding procedure was adopted under a load ratio of 0.1 and frequency of $15 \mathrm{~Hz}$. Test specimens have square cross-section $\left(7 \times 7 \mathrm{~mm}^{2}\right)$ with a single corner notch. After the fatigue crack growth testing, the fractured surface was investigated with scanning electron microscope (SEM). Cross section perpendicular to the crack growth direction is observed using optical microscope and SEM. 
Table 1 Chemical composition of experimental alloy (mass \%)

\begin{tabular}{ccccccccc}
\hline Al & Sn & Zr & Mo & Nb & Si & C & O & Ti \\
\hline 5.71 & 4.06 & 3.54 & 2.85 & 0.7 & 0.37 & 0.06 & 0.1 & Bal. \\
\hline
\end{tabular}

\section{Results and Discussion}

Microstructures. Figure 1 shows microstructures of samples after different heat treatments. The sample solution treated at $1323 \mathrm{~K}$ shows acicular microstructure whereas samples solution treated at $1273 \mathrm{~K}$ show bimodal microstructure which contains less amount of primary a phase in transformed b region. The sample with low forging ratio in the final forging contains the primary a phase in elongated shape, whereas with high forging ratio, the primary a phase shows equiaxed shape. The primary $b$ grain size of acicular sample is larger than the two types of bimodal samples due to the higher solution heat treatment temperature. Table 2 shows the summary of sample preparation condition and associate microstructures.

Table 2 Summary of sample preparation conditions

\begin{tabular}{lcc}
\hline Final forging & Heat treatment & Microstructure \\
\hline$\phi 80=>\phi 60$ & $1273 \mathrm{~K} / 3.6 \mathrm{ks} / \mathrm{AC}+908 \mathrm{~K} / 3.6 \mathrm{ks} / \mathrm{AC}$ & Bimodal (Elongated primary $\alpha)$ \\
\hline$\phi 60=>\phi 25$ & $1273 \mathrm{~K} / 3.6 \mathrm{ks} / \mathrm{AC}+908 \mathrm{~K} / 3.6 \mathrm{ks} / \mathrm{AC}$ & Bimodal (Equiaxed primary $\alpha)$ \\
\hline$\phi 60=>\phi 25$ & $1323 \mathrm{~K} / 3.6 \mathrm{ks} / \mathrm{AC}+908 \mathrm{~K} / 3.6 \mathrm{ks} / \mathrm{AC}$ & Acicular \\
\hline
\end{tabular}

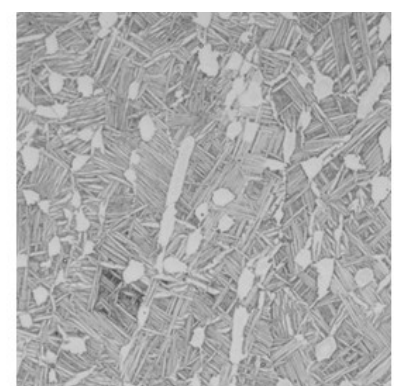

a) Bimodal (Elongated primary $\alpha$ )

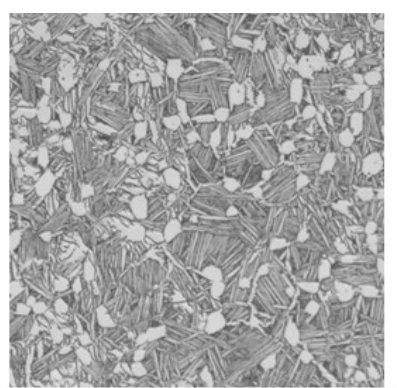

b) Bimodal (Equiaxed primary $\alpha$ )

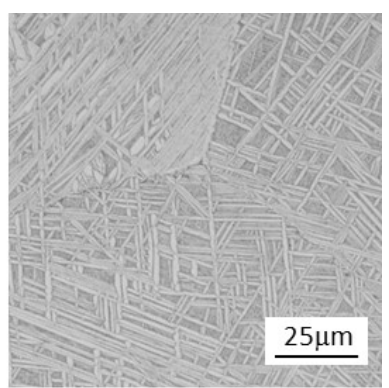

c) Acicular

Figure 1 Microstructures of samples

Influence of microstructures and environment on crack propagation behavior. Figure 2 shows the crack propagation resistance curves in air at room temperature for each microstructure. Acicular microstructure shows slightly lower crack propagation rate in comparison to the bimodal microstructures at higher DK regime. There is no apparent difference in crack propagation rate between the two types of bimodal microstructures. At room temperature, the microstructural influence seems to be minimal in the Paris' law regime. In Figure 3, the crack propagation rates of three types of microstructure do not differ to each other, at $823 \mathrm{~K}$, in air environment. In contrast, the acicular microstructure shows higher fatigue crack propagation resistance than the other two bimodal microstructures when testing in vacuum condition. In vacuum, the crack propagation rates of all microstructures are lower than those of in air condition. The morphology of the primary a in bimodal microstructure doesn't have any effect on the crack propagation rate in each condition. The fracture surface of acicular microstructure is rough and has coarser trans-granular propagation surface (figure 4). The rougher fracture surface of acicular microstructure is also confirmed from cross section perpendicular to crack propagation direction (Figure 5). 


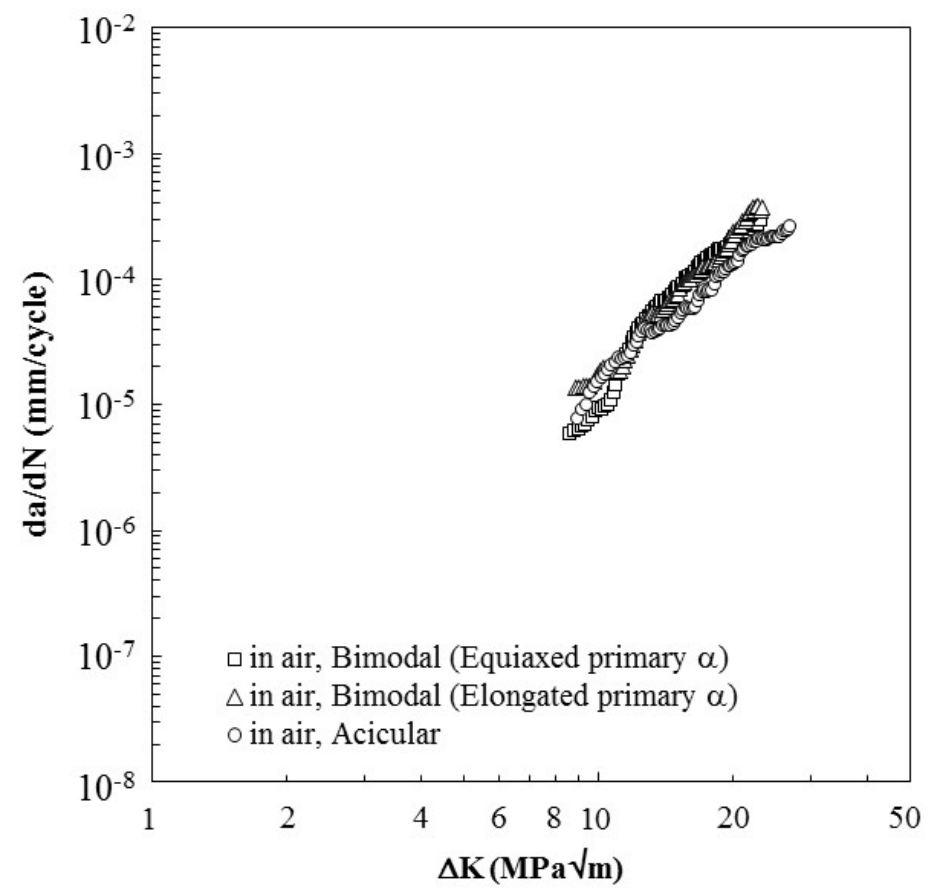

Figure 2 Crack propagation at room temperature

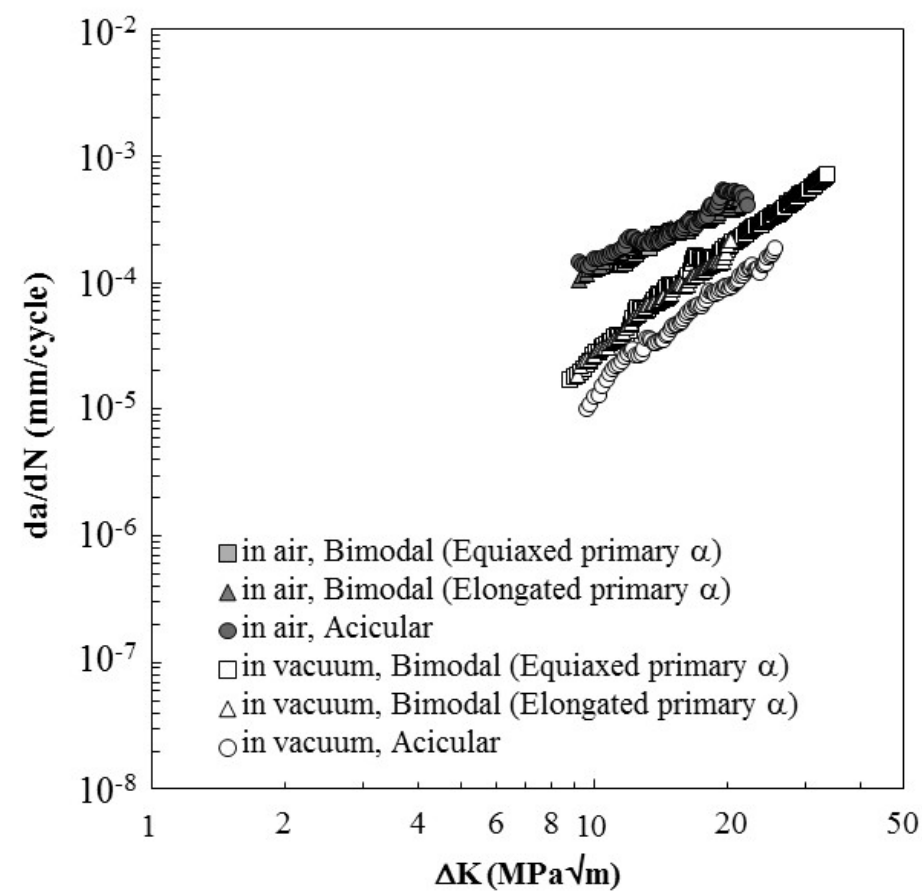

Figure 3 Crack propagation at $823 \mathrm{~K}$

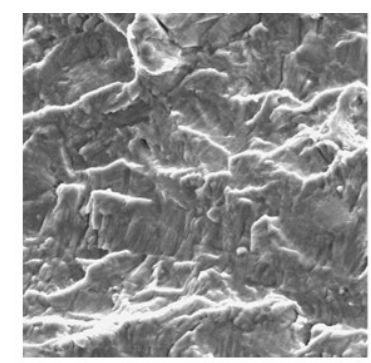

a) Bimodal (Elongated primary $\alpha$ )

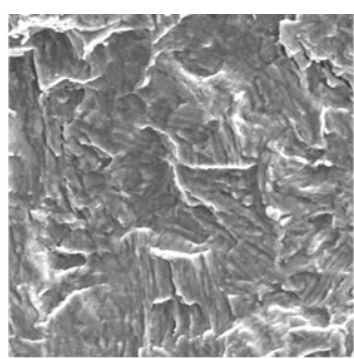

b) Bimodal (Equiaxed primary $\alpha$ )

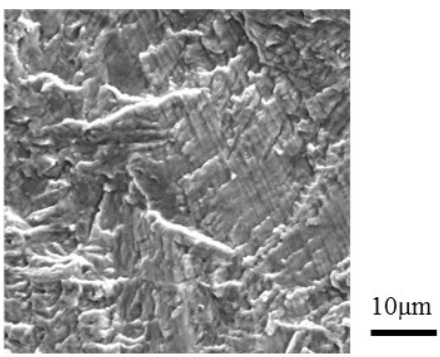

c) Acicular

Figure 4 Fracture surfaces, in vacuum at $823 \mathrm{~K}, \Delta \mathrm{K}=15 \mathrm{MPa} \sqrt{\mathrm{m}}_{\mathrm{m}}$ 


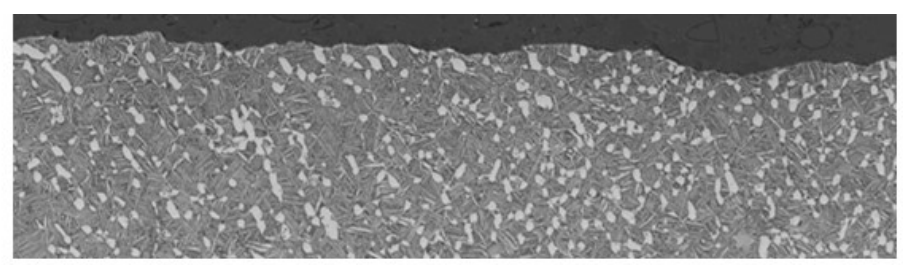

a) Bimodal (Elongated primary $\alpha$ )

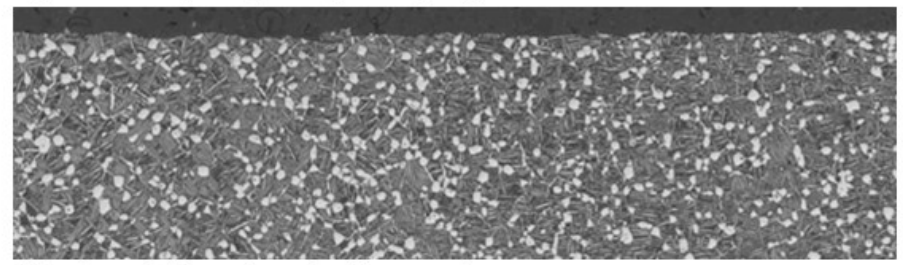

b) Bimodal (Equiaxed primary $\alpha$ )

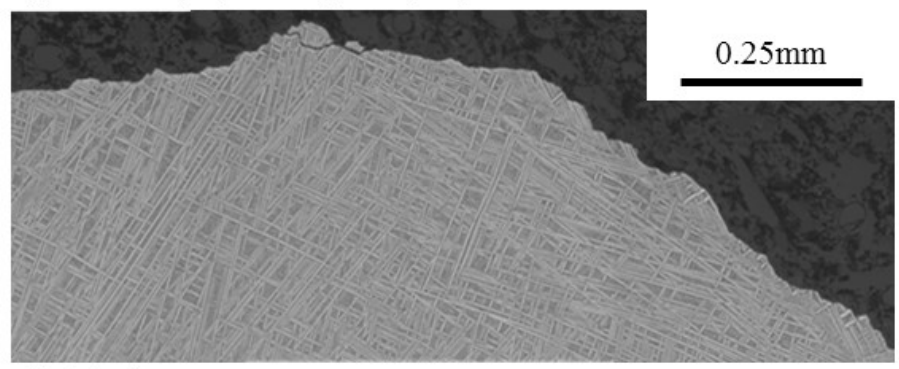

c) Acicular

Figure 5 Cross section of crack propagation at $823 \mathrm{~K}$, $\Delta \mathrm{K}=15 \mathrm{MPa} \sqrt{\mathrm{m}}$, crack propagation direction = left to right

Influence of microstructures on DKth. Figure 6 shows the near threshold fatigue crack propagation resistance curves in air at $823 \mathrm{~K}$ obtained with load shedding procedure. $\mathrm{da} / \mathrm{dN}$ for acicular microstructure rapidly decrease with the decrease of DK and its threshold is higher than other two bimodal microstructure. The da/dN vs DK curves of two bimodal microstructures are almost overlapping in the Paris' law region, but the bimodal with equiaxed primary a exhibits a slightly higher threshold value. Figure 7 shows the fracture surfaces near the threshold of each microstructure. On the fracture surface of bimodal microstructure with elongated primary a, micro facet are observed. This suggests that if the crack tip encounters the elongated coarse primary a, crack propagates into the primary a, thus the elongated a shows lower resistance for crack closure than equiaxed a, which is fine and distributed uniformly and less detrimental. In acicular microstructure, fracture surface shows Widmanstatten-like pattern of a platelets, suggesting that frequent change of the direction of a plates is reason for higher threshold. 


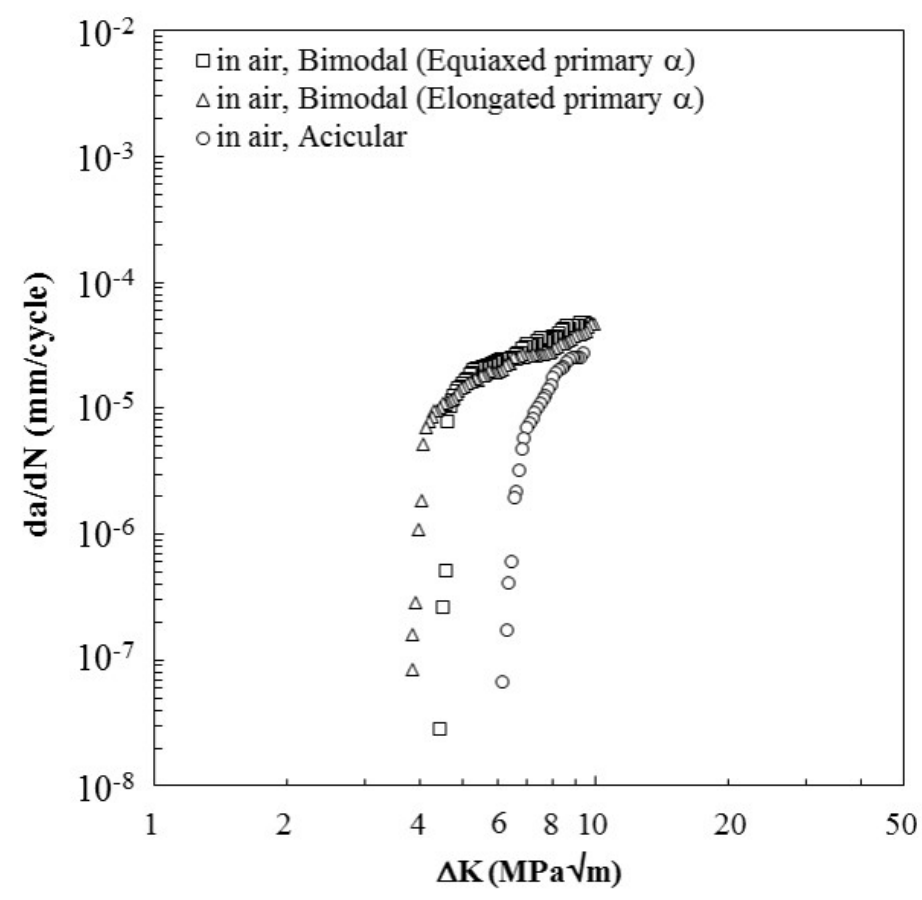

Figure 6 Crack propagation at $823 \mathrm{~K}$

Load shedding test with $15 \mathrm{~Hz}, \mathrm{R}=0.1$

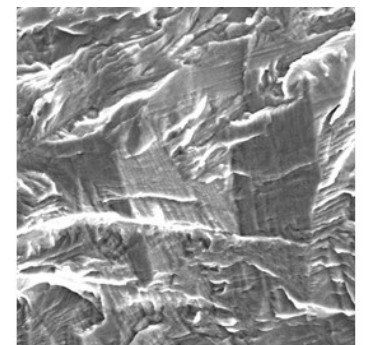

a) Bimodal (Elongated primary $\alpha$ )

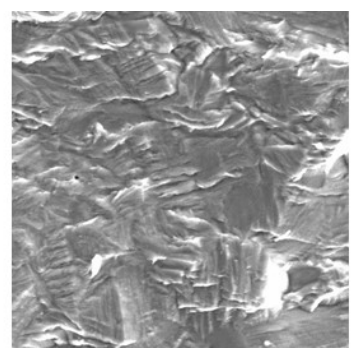

b) Bimodal (Equiaxed primary $\alpha$ )

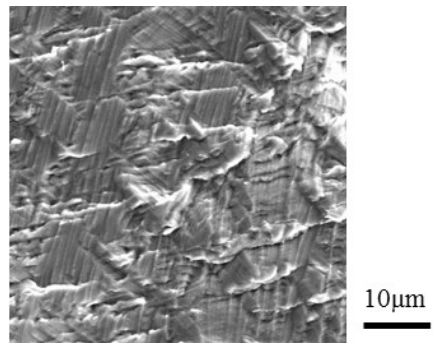

c) Acicular

Figure 7 Fracture surfaces, in vacuum at $823 \mathrm{~K}$,

a) $\Delta \mathrm{K}=4 \mathrm{MPa} \sqrt{\mathrm{m}}, \mathrm{b}) \Delta \mathrm{K}=5 \mathrm{MPa} \sqrt{\mathrm{m}}, \mathrm{c}) \Delta \mathrm{K}=6.5 \mathrm{MPa} \sqrt{\mathrm{m}}_{\mathrm{m}}$,

\section{Summary}

The microstructures and the environmental effect on the crack propagation properties of DAT54 were investigated.

1. Acicular microstructure shows higher fatigue crack propagation resistance than bimodal microstructure when testing in vacuum condition.

2. Acicular microstructure has a higher threshold than the bimodal microstructure.

3. The morphology of primary a do not influence fatigue crack propagation resistance in stable crack growth (Paris') regime.

\section{References}

[1] Titanium: A Technical Guide, 2nd Edition ASM international, (2000)

[2] A.K. Gogia, Defence Science Journal, 55-2 (2005) 149-173

[3] K. Yamada, T. Noda, T. Iikubo, T.Ikushima and H. Hattori, Proceeding of the 3rd Japan International SAMPE Symposium, (1993)1926

[4] T. Noda, M. Okabe, S. Isobe, S. Nishikiori and H. Hattori, Proceedings of 8th World Conference on Titanium, (1995)

[5] T. Noda, M. Okabe, S. Isobe, Denkiseikou, 67-2 (1996) 103-107 